\title{
An Alumina Standard Reference Material for Resonance Frequency and Dynamic Elastic Moduli Measurement I. For Use at $25^{\circ} \mathrm{C}$
}

\author{
R. W. Dickson and J. B. Wachtman, Jr. \\ Institute for Materials Research, National Bureau of Standards, Washington, D.C. 20234
}

(February 3, 1971)

\begin{abstract}
Bars of sintered polycrystalline alumina were machined to nominal dimensions of 12.7 by 1.27 by $0.32 \mathrm{~cm}$. Surfaces were machined flat and parallel. The mass, dimensions, and resonance frequencies (flexural and torsional) were measured at $25^{\circ} \mathrm{C}$. The exact frequency is specified for each bar and is typically about $2030 \mathrm{~Hz}$ for flexural resonance and $11250 \mathrm{~Hz}$ for torsional resonance. The effect of suspension loading on resonance frequency was determined and a correction made. Each bar can be used as a frequency standard with an uncertainty for values measured in air of about $\pm 0.03 \mathrm{~Hz}$ for flexure and $\pm 0.08 \mathrm{~Hz}$ for torsion. The effect of atmosphere on resonance frequency was determined and a correction was made for this effect. The uncertainty for resonance frequencies in vacuum is about $\pm 0.06 \mathrm{~Hz}$ for flexure and $\pm 0.18 \mathrm{~Hz}$ for torsion. Each bar can also be used as a dynamic elasticity standard with an uncertainty estimated to be about 0.2 percent for the shear modulus and 0.4 percent for Young's modulus.
\end{abstract}

Key words: Alumina; elastic modulus; resonance frequency; shear modulus; standard reference material; Young's modulus.

\section{Introduction}

Elastic moduli of solids are of interest both as fundamental data needed in the calculation of many solid state properties and as engineering data $[1] .^{1}$ Modern sound velocity and resonance techniques permit their determination to high accuracy provided that the mass and demensions of specimens can be accurately determined and provided that care is taken to eliminate or allow for certain loading effects. One popular technique is to determine the frequencies of the fundamental normal modes of vibration by the Forster method [2] in which a slender rod or bar is suspended horizontally on two fine wires or threads passing around the bar near the nodes of vibration. One wire is vibrated by a driver energized by a variable frequency oscillator. The other wire is attached to a detector. The driving frequency is varied until the desired mode of resonance (usually flexural or torsional) is excited and the frequency at resonance is measured. Procedures to identify the mode which is excited and accurate equations for calculating elastic moduli from these frequencies have been described [3].

The simplicity of the Forster method and its adaptability to measurements at high temperature have led to its widespread use. The accuracy with which fre-

Figures in brackets indicate the literature references at the end of this paper. quency can be measured with a crystal-controlled counter and the reproducibility of a given resonance frequency in a particular experimental arrangement sometimes obscures the fact that serious systematic errors can be present. The two most gross errors are the improper identification of the vibrational mode of the specimen which is excited or the exciting of a vibration of some part of the apparatus other than the specimen. Such errors may appear unlikely to pass undetected, but experience in consulting with operators just beginning to use the method has shown that such errors do occur. More subtle errors which are usually smaller and may pass unnoticed even by experienced operators include loading effects caused by the suspension or the surrounding atmosphere and temperature errors. The loading effects cause the specimen to resonate at a frequency slightly different from that of free vibration. The free vibration required for the specimen also makes it impossible to contact the specimens with a thermocouple unless the latter is used as one of the suspensions. This is usually undesirable because of the mechanical characteristics of thermocouple wire. Ordinarily a thermocouple placed very near the specimen is used to measure the temperature. The temperature difference between this couple and the specimen may be appreciable in high temperature measurements. It is, therefore, very useful for an operator to have a standard specimen with accurately known resonance frequencies and to have the temperature de- 
pendence of these frequencies in order to estimate the magnitude of these errors in his apparatus. The calculation of elastic moduli from resonance frequencies is sufficiently complicated that an example is useful for this purpose also. The complexity in these calculations arises because for a complete determination of the two independent moduli an iteration process is required to solve the simultaneous equations.

The foregoing are the primary reasons leading to the development of a dynamic elasticity standard. A secondary motivation is the possibility of using the same bars also as a standard for static measurement of Young's modulus in flexure. The static (isothermal) moduli should be less than the dynamic (adiabatic) moduli by a small amount calculable from an equation given, for example, by Nye [4]. For alumina the difference for Young's modulus is only 0.2 percent. Static flexural measurements, when carefully made and correctly analyzed show good agreement with dynamic measurements when this small difference is allowed for. Sources of error (up to several percent) exist in static measurement techniques which are difficult to locate and eliminate. Thus, dynamic standards might be useful for debugging static measurements.

The present elasticity standards were chosen to meet the following criteria: (1) They should be in a size range normally used for dynamic elasticity measurements. (2) They should permit very accurate values of resonance frequencies at $25^{\circ} \mathrm{C}$ to be certified for use in checking room temperature measurement procedure. (3) Their size and shape should permit accurate values of elastic moduli at $25^{\circ} \mathrm{C}$ to be calculated and certified. (4) The material used for the standard should be stable over the temperature range 25 to $1000{ }^{\circ} \mathrm{C}$ to permit certification of the ratio of frequency at elevated temperature to frequency at $25^{\circ} \mathrm{C}$ over this temperature range (from this information the frequencies themselves and the elastic moduli can be calculated over this temperature range).

\section{Material}

A standard elasticity bar should certainly be stable under normal use. The most likely sources of trouble with these bars are mechanical abrasion and thermal effects. A standard elasticity bar should always be handled with care so that damage from abrasions is not likely, but it is desirable that the material of the bar be sufficiently hard so that it would not be scratched by contact with metals. The bar should withstand heating in air to $1000{ }^{\circ} \mathrm{C}$ without change. These requirements suggest the use of a hard, dense oxide.

Fused silica was considered for this use and would apparently be quite suitable at $25{ }^{\circ} \mathrm{C}$. It possesses the advantages of elastic isotropy and of a high degree of homogeneity. However, the density changes slowly with time at $903{ }^{\circ} \mathrm{C}$ [5] so that the temperature range for use would be limited to somewhat below $900{ }^{\circ} \mathrm{C}$. Furthermore, devitrification at the surface occurs slowly at temperatures near $1000{ }^{\circ} \mathrm{C}$; its rate may depend on atmosphere and surface condition. Fused silica was therefore not chosen despite its homogeneity and ready availability because of the uncertainty about the temperature limit which would certainly have to be below $900^{\circ} \mathrm{C}$.

Polycrystalline alumina is elastically isotropic if formed by a process which does not produce a preferred orientation. It is even harder than fused silica so that it is very abrasion resistant. Polycrystalline alumina is normally porous; this reduces the elastic moduli but is not objectional unless the amount of porosity varies sufficiently with position to cause an unacceptable degree of inhomogeneity. A process for the production of nearly pore-free polycrystalline alumina has been developed and thin pieces are available commercially [6-9]. This process requires the presence of a small amount of $\mathrm{MgO}$ to reduce the rate of grain growth. The amount of $\mathrm{MgO}$ used (typically $0.25 \mathrm{wt} \%$ ) is chosen to be within the range of solid solubility at the sintering temperature (typically $1850{ }^{\circ} \mathrm{C}$ ). The extent of solid solubility depends on atmosphere and grain size; more importantly, the limit of solid solubility decreases with decreasing temperature below $1730{ }^{\circ} \mathrm{C}[10]$. Alumina produced by this process will apparently be in a metastable state at temperatures sufficiently below the sintering temperature. No work on the rate of precipitation of excess $\mathrm{MgO}$ at $1000{ }^{\circ} \mathrm{C}$ has been located, but the strong temperature dependence of diffusion rates in alumina suggests that at temperatures below $1200{ }^{\circ} \mathrm{C}$ precipitation would be too slow to be significant in a period of 1000 hours. Polycrystalline alumina was therefore chosen and is believed to be sufficiently stable at $1000{ }^{\circ} \mathrm{C}$ for the present purposes although its behavior over extremely long times is not known. After consultation with R. C. Anderson [11] and P. J. Jorgensen [12] it was decided to use 0.1 percent $\mathrm{MgO}$ and to isostatically cold press and sinter a single block of nominal dimensions $2^{1 / 4}$ by $25 / 8$ by $47 / 8$ in from which 40 specimen bars would be machined. The single-block approach offered the advantages of chemical homogeneity of the starting powder and of lower cost. Regions near the center of an isostatically cold pressed and sintered block are typically more porous than those near the surface, and it was recognized that the large size chosen might result in appreciable total porosity and some variation in porosity throughout the block. It was believed, however, that these effects would be small enough to be acceptable, and the single block was manufactured. Sintering was carried out under the direction of P. J. Jorgensen [12].

The sintered block was diamond ground to produce flat surfaces with opposite surfaces parallel and adjacent surfaces perpendicular. The density was determined from the mass (corrected for air bouyancy) and the dimensions (measured after overnight equilibration in a constant temperature room at $23.9{ }^{\circ} \mathrm{C}$ ). The result was $3.933 \pm 0.002 \mathrm{gm} / \mathrm{cm}^{3}$ where the uncertainty is the gross standard deviation calculated from the individual standard deviations of the mass and length determinations. The density of pure single crystal alumina is $3.986 \mathrm{gm} / \mathrm{cm}^{3}$ as determined by hydrostatic weighing [13] or $3.987 \mathrm{gm} / \mathrm{cm}^{3}$ from $\mathrm{x}$-ray parameter measure- 
ment [14]. On this basis, the average porosity of the block was 1.3 percent.

The block was marked off into individual specimens as shown in figure 1 and specimen numbers $\mathrm{Al}, \mathrm{A} 2, \ldots$

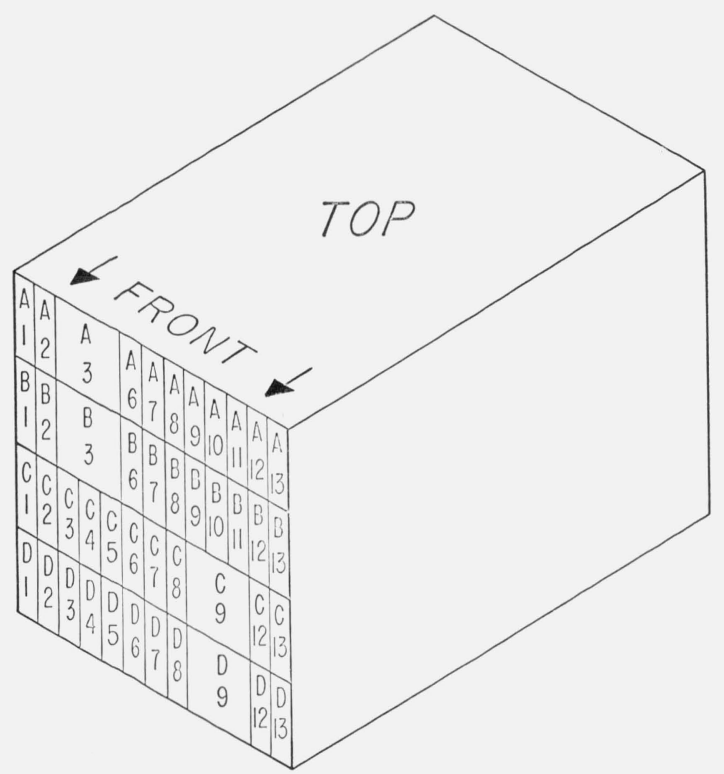

FIGURE 1. Pattern of resonance bars machined from original cold-pressed and sintered alumina block.

D13 were lightly inscribed on one end with a diamond point scriber. The block was then diamond sawed into bars in accordance with this pattern. The four large bars A3, B3, C9, and D9 were reserved for possible machining of cylinders and the remaining 40 bars were prepared as elasticity standards. Each bar was given a fine diamond grind to produce flat surfaces with opposite sides parallel and adjacent sides perpendicular. The mass (corrected for air bouyancy) and the dimensions of each bar are given in table 1 .

Bars A3 and B3 were examined by x-ray techniques. The prime concern was the possible existence of a preferred orientation of the crystallites which would cause the specimens to be anisotropic. Back-reflection x-ray patterns showed no such preferred orientation [15]. They also yielded the information that the average crystallite size (determined from the number of spots for a given reflection, the beam size, and the adsorption) was $24 \mu \mathrm{m}$. High-resolution high-intensity diffractometer patterns showed almost exclusively the $\alpha$-alumina phase as expected. A very weak pattern, identified as due to the presence of $\mathrm{MgAl}_{2} \mathrm{O}_{4}$ (spinel), was also present; the intensity, however, indicated that the proportion of $\mathrm{MgAl}_{2} \mathrm{O}_{4}$ was much less than one percent.

\section{Experimental Procedure and Frequency Corrections}

The general procedure for exciting a resonance and probing the vibrational pattern with a pickup to identify the vibrational mode has been described by Spinner and Tefft [3], who also describe the electronic components required. The following specific items of equipment were used in the present work but many similar components exist and would presumably be equally satisfactory. The driver was an Astatic model M 41-8 phonograph record recording head. It was driven by a Hewlett-Packard $463-A$ precision amplifier driven in turn by a General Radio frequency synthesizer Model 1163-AR7C with automatic sweep unit. The frequency was monitored with a Beckman timer Model 6147 which in turn was standardized with the NBS $100 \mathrm{kHz}$ frequency so that the driving frequency measurement should be accurate to 1 part in $10^{6}$. The pickup was an Astatic $\mathrm{L}-121$ crystal phonograph cartridge for use in air or an Astatic 51-3 ceramic phonograph cartridge for use at reduced pressures. The signal was amplified by an Applied Cybernetics System Model 1A260V battery-powered lownoise amplifier. The signal was continuously monitored on a Dumont Model 304-AR oscilloscope which was supplemented for measurements of response to automatic frequency sweep by a Tektronix type 564 storage oscilloscope with a type $3 \mathrm{~A} 72$ dual-trace plug-in amplifier and a type 2B67 plug-in time base. The use of a frequency synthesizer having a sweep unit is very desirable for this work which requires the combined capabilities of searching over wide frequency ranges (to find the resonances) and of very precise tuning (to determine the frequency of a resonance response as little as $0.1 \mathrm{~Hz}$ broad). The automatic feature of the sweep unit used allowed smooth frequency change (typically $1 \mathrm{~Hz}$ frequency change in 10 seconds) in locating the exact maximum of the vibrational amplitude corresponding to resonance. Even with very low sweep rates the slow response of the specimens caused a shift of the maximum amplitude of response from the resonance frequency, but by sweeping in both directions, recording the amplitudes on the storage oscilloscope, and noting how the maximum responses approached each other as the sweep rate was lowered this effect could be overcome.

Each bar was suspended horizontally using fine silk thread and the loop method of suspension [16] in which both the thread from the driver needle and the thread from the pickup needle are cemented to their respective needles at two points. Each thread then forms a continuous loop and supports the specimen without a knot at any point. Approximate values of the flexural and torsional resonance frequency were determined with the thread placed symmetrically some distance from the nodes. The vibrational pattern was probed to verify the identification of the nodes as previously described [3]. The measured internal friction of lowloss specimens is strongly affected by the suspension position [17]; the resonance frequency is affected to an extent which is much smaller but which is still significant for the present accurate frequency determinations. As in the previous work [17], a specimen was suspended with the driver and pickup threads positioned symmetrically. To obtain a correction for the effect of the suspension one of the specimens was suspended at several pairs of symmetrically located 
TABLE 1. Properties of alumina standard reference bars for frequency and dynamic elastic moduli at $25{ }^{\circ} \mathrm{C}$ in vacuum $^{\text {a }}$

\begin{tabular}{|c|c|c|c|c|c|c|c|c|c|c|}
\hline $\begin{array}{c}\text { Bar } \\
\text { Number }\end{array}$ & Mass & Length & Width & Thickness & Density & $\begin{array}{c}\text { Flexural } \\
\text { Frequency }\end{array}$ & $\begin{array}{l}\text { Torsional } \\
\text { Frequency }\end{array}$ & $\begin{array}{l}\text { Young's } \\
\text { Modulus }\end{array}$ & $\begin{array}{c}\text { Shear } \\
\text { Modulus }\end{array}$ & $\begin{array}{c}\text { Poisson's } \\
\text { Ratio }\end{array}$ \\
\hline & Grams & $\mathrm{cm}$ & $\mathrm{cm}$ & $\mathrm{cm}$ & $\mathrm{g} / \mathrm{cm}^{3}$ & $H z$ & $H z$ & $10^{\prime \prime} \mathrm{N} / \mathrm{m}^{2}$ & $10^{\prime \prime} \mathrm{N} / \mathrm{m}^{2}$ & \\
\hline Al & 20.5174 & 12.7003 & 1.271 & 0.3222 & 3.944 & 2037.56 & 11249.5 & 3.900 & 1.581 & 0.233 \\
\hline A2 & 20.4679 & 12.7002 & 1.271 & .3223 & 3.934 & 2032.37 & 11224.3 & 3.869 & 1.569 & .232 \\
\hline A6 & 20.4364 & 12.7000 & 1.271 & .3223 & 3.928 & 2027.82 & 11203.5 & 3.846 & 1.561 & .232 \\
\hline A7 & 20.4388 & 12.7001 & 1.271 & .3223 & 3.929 & 2027.46 & 11200.4 & 3.844 & 1.560 & .232 \\
\hline A8 & 20.4458 & 12.7003 & 1.271 & .3226 & 3.926 & 2027.57 & 11201.8 & 3.835 & 1.557 & .231 \\
\hline A9 & 20.4686 & 12.7003 & 1.271 & .3228 & 3.929 & 2030.70 & 11216.1 & 3.847 & 1.562 & .232 \\
\hline A 10 & 20.4708 & 12.7005 & 1.271 & .3225 & 3.932 & 2031.64 & 11220.8 & 3.860 & 1.566 & .232 \\
\hline All & 20.4972 & 12.7006 & 1.271 & .3226 & 3.936 & 2035.43 & 11237.8 & 3.876 & 1.572 & .233 \\
\hline A 12 & 20.5017 & 12.7008 & 1.271 & .3222 & 3.941 & 2037.12 & 11247.6 & 3.898 & 1.580 & .233 \\
\hline Al3 & 20.5579 & 12.7011 & 1.271 & .3223 & 3.951 & 2043.29 & 11279.6 & 3.928 & 1.592 & .233 \\
\hline B1 & 20.4863 & 12.6998 & 1.271 & 0.3224 & 3.937 & 2030.55 & 11216.5 & 3.863 & 2.568 & 0.232 \\
\hline $\mathrm{B} 2$ & 20.4270 & 12.6998 & 1.271 & .3223 & 3.926 & 2027.62 & 11200.6 & 3.844 & 1.560 & .232 \\
\hline B6 & 20.2490 & 12.6995 & 1.271 & .3221 & 3.894 & 2002.33 & 11071.3 & 3.720 & 1.513 & .230 \\
\hline B7 & 20.2543 & 12.6995 & 1.271 & .3225 & 3.891 & 2000.70 & 11062.4 & 3.702 & 1.506 & .229 \\
\hline B8 & 20.2694 & 12.6996 & 1.271 & .3226 & 3.893 & 2003.93 & 11079.0 & 3.714 & 1.510 & .229 \\
\hline B9 & 20.2847 & 12.6996 & 1.271 & .3227 & 3.895 & 2005.27 & 11085.2 & 3.719 & 1.513 & .230 \\
\hline B10 & 20.3098 & 12.6998 & 1.271 & .3226 & 3.900 & 2009.27 & 11107.4 & 3.741 & 1.521 & .230 \\
\hline B11 & 20.3535 & 12.7002 & 1.271 & .3221 & 3.914 & 2015.61 & 11141.7 & 3.790 & 1.540 & .230 \\
\hline B12 & 20.4553 & 12.7005 & 1.271 & .3223 & 3.931 & 2029.48 & 11213.0 & 3.856 & 1.566 & .231 \\
\hline B13 & 20.5947 & 12.7016 & 1.271 & .3226 & 3.955 & 2046.57 & 11298.6 & 3.937 & 1.596 & .233 \\
\hline C1 & 20.5713 & 12.7008 & 1.271 & 0.3227 & 3.949 & 2044.29 & 11289.1 & 3.919 & 1.590 & 0.233 \\
\hline C2 & 20.4124 & 12.6998 & 1.271 & .3227 & 3.920 & 2022.39 & 11177.9 & 3.808 & 1.548 & .230 \\
\hline C3 & 20.2913 & 12.6996 & 1.271 & .3220 & 3.905 & 2008.83 & 11109.9 & 3.759 & 1.529 & .230 \\
\hline C4 & 20.2657 & 12.6995 & 1.271 & .3224 & 3.895 & 2003.08 & 11079.2 & 3.717 & 1.512 & .229 \\
\hline C5 & 20.2505 & 12.6996 & 1.271 & .3225 & 3.891 & 2000.34 & 11065.0 & 3.701 & 1.506 & .229 \\
\hline C6 & 20.2209 & 12.6996 & 1.271 & .3221 & 3.890 & 1998.10 & 11054.9 & 3.700 & 1.506 & .229 \\
\hline C7 & 20.2274 & 12.6995 & 1.271 & .3221 & 3.891 & 1998.73 & 11058.1 & 3.705 & 1.508 & .229 \\
\hline C8 & 20.2634 & 12.6997 & 1.271 & .3227 & 3.891 & 2002.42 & 11075.3 & 3.705 & 1.508 & .229 \\
\hline C.12 & 20.4375 & 12.7005 & 1.271 & .3221 & 3.932 & 2026.81 & 11202.1 & 3.851 & 1.564 & .231 \\
\hline C13 & 20.5306 & 12.6999 & 1.271 & .3227 & 3.942 & 2038.65 & 11258.3 & 3.892 & 1.579 & .232 \\
\hline D1 & 20.5638 & 12.7006 & 1.271 & 0.3226 & 3.950 & 2043.27 & 11281.4 & 3.919 & 1.589 & 0.233 \\
\hline $\mathrm{D} 2$ & 20.5251 & 12.7003 & 1.271 & .3227 & 3.942 & 2038.87 & 11260.4 & 3.892 & 1.579 & .232 \\
\hline D3 & 20.5001 & 12.7004 & 1.271 & .3228 & 3.935 & 2035.35 & 11243.1 & 3.869 & 1.570 & .232 \\
\hline D4 & 20.4892 & 12.7003 & 1.271 & .3226 & 3.935 & 2033.30 & 11234.1 & 3.866 & 1.570 & .232 \\
\hline D5 & 20.4838 & 12.7002 & 1.271 & .3224 & 3.937 & 2033.87 & 11237.6 & 3.876 & 1.573 & .232 \\
\hline D6 & 20.4787 & 12.7004 & 1.271 & .3225 & 3.935 & 2031.77 & 11227.5 & 3.863 & 1.569 & .231 \\
\hline D7 & 20.4863 & 12.7004 & 1.271 & .3227 & 3.934 & 2033.46 & 11234.8 & 3.863 & 1.568 & .232 \\
\hline D8 & 20.4796 & 12.7006 & 1.271 & .3226 & 3.934 & 2033.59 & 11236.1 & 3.867 & 1.570 & .231 \\
\hline $\mathrm{D} 12$ & 20.5332 & 12.7013 & 1.271 & .3226 & 3.942 & 2039.18 & 11259.8 & 3.896 & 1.580 & .233 \\
\hline D13 & 20.5710 & 12.7007 & 1.271 & .3227 & 3.948 & 2045.14 & 11290.3 & 3.923 & 1.591 & .233 \\
\hline
\end{tabular}

${ }^{a}$ For use in air subtract $0.99 \mathrm{~Hz}$ from flexural resonance frequency and $2.25 \mathrm{~Hz}$ from torsional resonance frequency.

Estimated accuracy is given in terms of standard deviation based on repeated measurements for length, width, and thickness. For other quantities the estimated uncertainty is based on estimates of the accuracy of the instruments involved, the equations used, the correction factors, and the specimen homogeneity as described in the text. The estimated standard deviations are: mass $\pm 0.0001 \mathrm{gm}$, length \pm 0.0002 $\mathrm{cm}$, width $\pm 0.0001 \mathrm{~cm}$, thickness $\pm 0.0003 \mathrm{~cm}$, density $\pm 0.004 \mathrm{gm} / \mathrm{cm}^{3}$. The estimated uncertainties are: flexural frequency in vacuum \pm 0.06 $\mathrm{Hz}$, torsional frequency in vacuum $\pm 0.18 \mathrm{~Hz}$, Young's modulus $\pm 0.016 \times 10^{11} \mathrm{~N} / \mathrm{m}^{2}$, shear modulus $\pm 0.003 \times 10^{11} \mathrm{~N} / \mathrm{m}^{2}$, and Poisson's ratio \pm 0.005 . The values of resonance frequency in air, obtainable as described above, are more accurate than the vacuum values because they were directly determined. The corresponding estimated uncertainties are $\pm 0.03 \mathrm{~Hz}$ for the flexural resonance frequency and $\pm 0.08 \mathrm{~Hz}$ for the torsional resonance frequency in air at one atmosphere pressure.

points and a series of frequencies determined. The measured values for the fundamental flexural resonance pass through a minimum, taken as the value for free vibration in air, corresponding to suspension position at the nodes of vibration. One position of the suspension (near the nodes) was chosen as a "standard" position and a correction factor determined for this position. All specimens were measured with the sus- pension at this position and with the same suspension (i.e., the same threads and needles) used for all measurements. The measured frequency was then corrected to give the free resonance frequency of flexure in air at the test temperature by substracting $0.05 \mathrm{~Hz}$. For torsion the equivalent correction was made by subtracting $0.13 \mathrm{~Hz}$.

The temperature dependence in the vicinity of $25^{\circ} \mathrm{C}$ 
was next determined for two bars. The elastic moduli of alumina are known to vary smoothly with temperature and to be approximately linear near $25{ }^{\circ} \mathrm{C}[18,19]$. The temperature coefficients for the flexural and torsional resonance frequencies for these two bars were determined to be $-0.117 \mathrm{~Hz} /{ }^{\circ} \mathrm{C}$ and $-0.710 \mathrm{~Hz} /{ }^{\circ} \mathrm{C}$, respectively.

The bars are so nearly identical that the same correction factors for suspension effect and temperature can be used for all bars. As can be seen the correction factors for these suspensions and for minor deviations of the test temperature from $25{ }^{\circ} \mathrm{C}$ are small (small enough to be neglected in most elastic moduli measurements), but they are not negligible for the present purpose. Accordingly, the following procedure was adopted. A careful measurement of the flexural and torsional resonance frequencies for each bar was made by suspending the bar within a heavy-walled, acoustically insulated box and allowing it to come to temperature equilibrium. The temperature was read to $0.1{ }^{\circ} \mathrm{C}$ and each measured resonance frequency was taken as the average of the value corresponding to the maximum amplitude of vibration for a slow increasing-frequency sweep and a decreasing-frequency sweep. Values were determined to $0.01 \mathrm{~Hz}$. These values, corrected as above for temperature and suspension effect are the free resonance frequencies in air at $25{ }^{\circ} \mathrm{C}$.

The atmosphere is known to affect both the resonance frequency and damping and it is sometimes suggested, especially for damping, that the viscous drag on the moving specimen is responsible. While viscous drag may be important for certain types of internal friction measurements (e.g., the torsion of thin cylinders)

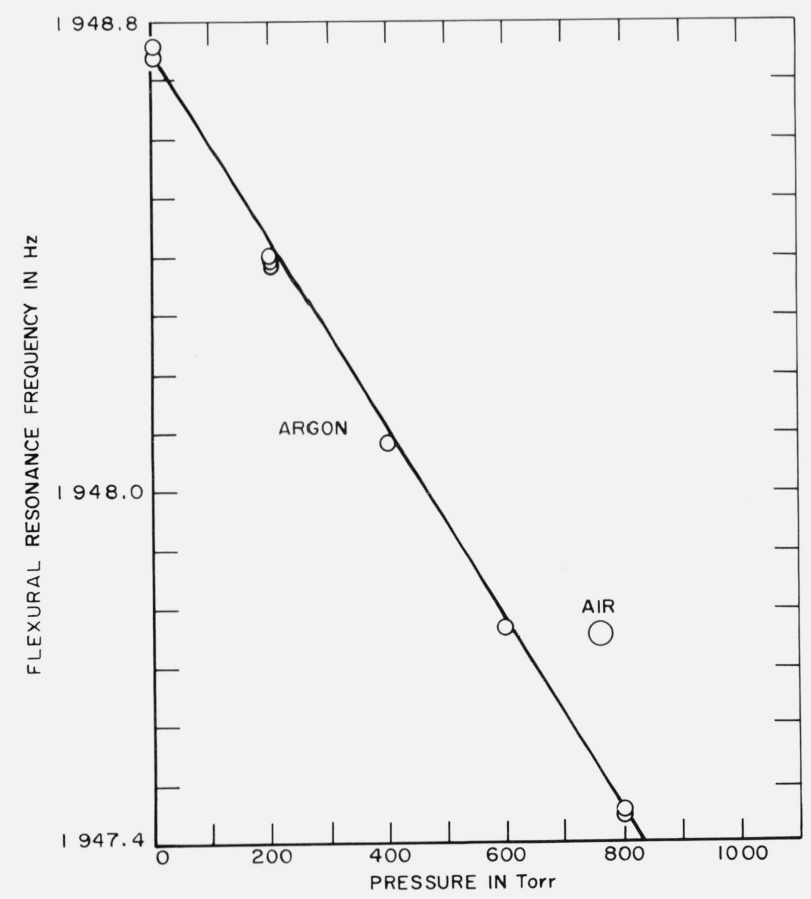

Figure 2. Flexural resonance frequency as a function of pressure of argon.

Single point is for air at one atmosphere pressure.

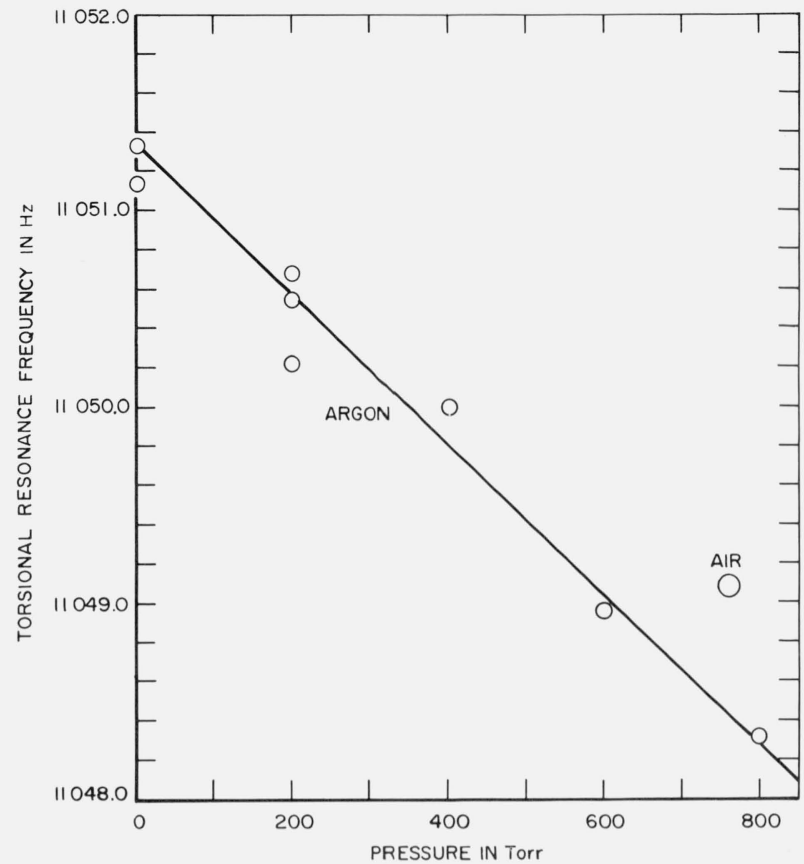

FigURE 3. Torsional resonance frequency as a function of pressure of argon.

Single point is for air at one atmosphere pressure.

it is apparently not the predominant atmospheric effect on the frequencies of specimens of the present size and shape. To determine the cause and size of the effect of atmosphere on frequency, specimens were suspended in a large vacuum chamber which also contained the driver and pickup. The resonance frequency was first measured in air. The chamber was then evacuated and filled in stages with argon. Figures 2 and 3 show the dependence of the flexural and torsional resonance frequencies upon pressure of argon. The straight lines were drawn by a visual fit. Figures 2 and 3 show that the pressure dependence of the resonance frequencies is essentially linear over the entire range of measurement. This differs markedly from the bahavior of the viscosity which changes little down to pressures of about $1 \mathrm{~mm}$ of $\mathrm{Hg}$ and then decreases rapidly with futher lowering of the pressure. Such a linear dependence upon pressure is, however, to be expected from the variation of the acoustic impedance with pressure. For small acoustical loading the frequency should change in proportion to the acoustic impedance. The latter is proportional to $\rho c$ which for an ideal gas is proportional to $(\rho p)^{1 / 2}$ or to $\gamma^{1 / 2} M^{1 / 2} p$ where $\rho$ is density, $c$ is velocity of sound, $p$ is pressure, $\gamma=C_{p} / C_{1}$ and $M$ is mean molecular weight [20]. The molecular weights of argon and air are 39.95 and 29.12 , respectively [21]; their $\gamma$ values are 1.668 and 1.403 [20]. Thus the ratio of the shift of resonance frequency in going from vacuum to $1 \mathrm{~atm}$ pressure of argon to the same shift for air is predicted to be $(\gamma M)_{\text {argon }}^{1 / 2} /(\gamma M)_{\text {air }}^{1 / 2}=1.277$. The measured frequency shifts are $1.24 \mathrm{~Hz}$ and $0.99 \mathrm{~Hz}$ for flexure giving a ratio of 1.25; the corresponding values for torsion are $2.90 \mathrm{~Hz}$ and $2.25 \mathrm{~Hz}$ giving a ratio of 1.29 . The 
bars are sufficiently alike that the same frequency shifts apply to all bars. The free resonance frequency at $25{ }^{\circ} \mathrm{C}$ in vacuum is thus given by the free resonance frequency at $25^{\circ} \mathrm{C}$ in air plus a correction factor which is $0.99 \mathrm{~Hz}$ for flexure and $2.25 \mathrm{~Hz}$ for torsion.

\section{Calculation of Elastic Moduli and Estimates of Error}

Spinner and Tefft [3] have reviewed the equations for calculation of elastic moduli of homogeneous, isotropic material from the resonance frequencies of slender bars. Their recommended equations were used. The shear modulus, $G$ was calculated from the density, $\rho$, length, $l$, and fundamental torsional resonance frequency, $f_{t}$, using

$$
G=\rho R\left(2 l f_{t}\right)^{2}
$$

where $R$ is a shape factor given by

$$
\begin{gathered}
R=\left[\frac{1+\left(\frac{b}{a}\right)^{2}}{4-2.521 \frac{a}{b}\left(1-\frac{1.991}{\exp \left(\frac{\pi b}{a}\right)+1}\right)}\right]\left[1+\frac{0.00851 b^{2}}{l^{2}}\right] \\
-0.060\left(\frac{b}{a}\right)^{3 / 2}\left(\frac{b}{a}-1\right)^{2}
\end{gathered}
$$

in which $b$ is width and $a$ is thickness. The flexural motion is in the direction of the thickness.

Spinner and Tefft estimate that this calculation should give $G$ values accurate to within 0.2 percent when $b / l<0.3$ and $b / a<10$ as they are for the present specimens.

Young's modulus, $Y$, was calculated from

$$
Y=0.94642\left(\rho l^{4} f_{f}^{2} / a^{2}\right) T
$$

in which $f_{f}$ is the fundamental flexural resonance frequency and $T$ is a correction factor given by

$$
\begin{aligned}
T=1 & +6.585\left(1+0.0752 \mu+0.8109 \mu^{2}\right)\left(\frac{a}{l}\right)^{2}-0.868\left(\frac{a}{l}\right)^{4} \\
& -\frac{8.340\left(1+0.2023 \mu+2.173 \mu^{2}\right)(a / l)^{4}}{1+6.338\left(1+0.14081 \mu+1.536 \mu^{2}\right)(a / l)^{2}}
\end{aligned}
$$

in which $\mu$ is Poisson's ratio.

For each bar a single value of $G$ was calculated which does not require Poisson's ratio in the calculation. An initial value of $Y$ was calculated taking $T=1.000$ which is the value of $T$ for a very thin bar, i.e., for $t / l=0$. A value of Poisson's ratio was then calculated from

$$
\mu=(Y / 2 G)-1
$$

and $Y$ was recalculated using this value of $\mu$. This process was repeated until self consistent values of $Y$ and $\mu$ were obtained. The accuracy of this type of calculation for homogeneous bars of the length-tothickness ratio used here has been judged to be better than 0.1 percent judging from an empirical study with steel specimens by Spinner, Reichard, and Tefft [24].

The above estimates of uncertainty ${ }^{2}$ are those of the equations themselves. Additional uncertainty arises from variations in thickness (uncertainties associated with measurements of frequency, mass, length, and width are smaller). For the shear modulus the thickness enters only to the -1 power through the density. An uncertainty of 0.1 percent in the thickness (the probable error based on 5 measurements) is typical and gives an uncertainty (from this source alone) of about 0.1 percent in the shear modulus. For Young's modulus the thickness enters to the -3 power (including its presence in the density) giving an uncertainty (from this source alone) of 0.3 percent in Young's modulus.

The above considerations of error do not include the effect of inhomogeneous distribution of porosity. Porosity differences from bar to bar change elastic moduli values but this is fully taken into account in the calculations and does not introduce additional uncertainty into the moduli values provided that the porosity is homogeneously distributed within each bar. Examination of the density values in table 1 shows that the corner bars (A1, A13, D1, and D13 in fig. 1) form the most dense groups followed in order of decreasing density by the following groups: those having a face on the original surface $(\mathrm{B} 1, \mathrm{C} 1, \mathrm{~B} 13$, and C13), those having an edge on the original surface (A2, A6, A7, A8, A9, A10, A11, A12, D2, D3, D4, D5, D6, D7, D8, and D12), and those entirely within the original bar (B2, B6, B7, B8, B9, B10, B11, B12, C2, C3, C4, C5, C6, C7, C8, and C12). As mentioned previously, this type of porosity gradient is commonly observed in cold pressed and sintered bars. If the porosity distribution was the same for all planes parallel to the end of the block shown in figure 1 (no longitudinal component of the gradient); it could probably be ignored. However, there must be a similar gradient from end to end of the original large bar. It is probable that the lengthwise gradient is smallest in the four corner bars because the porosity is least and because these bars have directly experienced the applied pressure. Similarly, it is probable that the lengthwise porosity gradient increases in the order of decreasing density. If this effect introduces systematic error into the calculated moduli, we would expect plots of Young's modulus or the shear modulus as a function of porosity to give a different curve for each of the four groups of bars. In fact, all points fall on the same plot within the random scatter as judged by eye. This scatter is consistent with the above estimates of error due to thickness uncertainty; any

"2 The word "uncertainty," as used in this paper, means an estimated total uncertainty derived from the consideration of possible sources of error in all the measurements involved derived from the consideration of possible sources of error in all the measurements involved
in the determination of the studied property. The estimation is generally based on previous knowledge of the measuring processes involved; the estimates are not expressed in terms of exact statistical measures, such as standard deviations, because they comprise both random and systematic errors and are partly based on judgment rather than on repetitive measurements of the same quantity. 
error arising from inaccuracy of the equations would be a systematic error and so not reflected in the scatter on these plots. The maximum deviation from the curve for any bar is 0.3 percent for Young's modulus and 0.2 percent for the shear modulus.

Combining possible errors from the equations and the measurements we thus arrive at estimates of the uncertainty of 0.2 percent for the shear modulus and 0.4 percent for Young's modulus. These uncertainty values refer to the dynamic elastic moduli.

The static Young's modulus will be 0.2 percent less than the dynamic Young's modulus because of the change from adiabatic to isothermal conditions as mentioned previously. Determination of static elastic moduli in bending places a very similar, though not identical, stress field on a bar as resonance in the fundamental mode of flexure. We therefore expect inhomogeneous distribution of porosity to have approximately the same effect on the stiffness of a bar in dynamic or static flexure. In dynamic flexure inhonogeneous distribution of porosity could also shift resonance frequency (and therefore calculated moduli) through the change of inertia. As noted above, no appreciable difference in groups of bars of differing porosity ranges was detected so that we believe this dynamic effect is not appreciable and the same uncertainties should hold for static and dynamic moduli measured over the whole length of the bar. We do not recommend cutting a bar into pieces; the reported values may not apply to short pieces within the stated uncertainty limits because of porosity variation along the length of the bar. For very accurate static comparisons we recommend the use of the 8 high density bars (A1, A13, B1, B13, C1, C13, D1, D13) to minimize possible porosity gradient effects.

\section{Summary and Recommendations}

The resonance frequency of each bar is specified to the nearest $0.1 \mathrm{~Hz}$ for the torsional resonance in air at $1 \mathrm{~atm}$ pressure with an estimated uncertainty of $\pm 0.08 \mathrm{~Hz}$ (relative uncertainty of 0.0007 percent); for flexural resonance the frequency is specified to the nearest $0.01 \mathrm{~Hz}$ with an estimated uncertainty of $\pm 0.03 \mathrm{~Hz}$ (relative uncertainty of 0.0015 percent). These values correspond to free vibration, i.e., the specimen must be supported in such a way that the suspension does not add effective mass or stiffness. In most situations the suspension will affect the resonance frequency, perhaps by a few $\mathrm{Hz}$, unless care is taken. Use of one of the present bars will give the investigator an indication of how much his suspension is affecting the measured resonance frequency. He must not use the difference as a correction factor to apply to other materials, however, because the frequency shift caused by a given suspension may differ markedly for bars of different moduli, density, or size.

Chipping will affect the resonance frequencies. Each bar is quite strong and hard so that no chipping should occur with reasonable care, but impacts must be avoided. The mass of the bar can be redetermined as a confirmation that chipping has not occurred. If a bar is extremely clean and dry, electrostatic charging may cause a fluctuating apparent change in weight, but this effect does not occur in normal practice.

The dynamic elastic moduli are given with an estimated relative uncertainty of 0.2 percent for the shear modulus and 0.4 percent for Young's modulus. These estimates of uncertainty assume the use of the whole bar; cutting the bar into smaller pieces is not recommended because of possible porosity gradients.

Young's modulus in static flexure will be 0.2 percent less than the dynamic value because of the change from adiabatic to isothermal conditions. Use of one of the highest density bars is recommended for accurate work in static flexure.

\section{References}

[1] Wachtman, J. B., Jr., Elastic Deformation of Ceramics and Other Refractory Materials, pages 139-168 in "Mechanical and Thermal Properties of Ceramics", J. B. Wachtman, Jr., Ed., National Bureau of Standards Special Publication 303, May, 1969.

[2] Forster, F., Ein neues Messverfahren zur Bestimmung des Elastizitatemoduls und der Dampfung (New method for determination of modulus of elasticity and damping), Zeit schrift fur Metallkunde, 29.109-115 (1937).

[3] Spinner, S., and Tefft, W. E., A method for determining mechanical resonance frequencies and for calculating elastic moduli from these frequencies, Proc. ASTM 61, 1221-1238 (1961).

[4] Nye, J. F., Physical Properties of Crystals (Oxford University Press, 1964).

[5] Douglas, R. B., and Isard, J. O., Density changes in fused silica, J. Society Glass Technology 35, 206-225 (1951).

[6] Coble, R. L., Sintering crystalline solids: I, intermediate and final stage diffusion models, J. Appl. Phys. 32, 787-792 (1961).

[7] Coble, R. L., Sintering crystalline solids: II, experimental test of diffusion models in powder compacts, J. Appl. Phys. 32, 793-799 (1961).

[8] Coble, R. L., Sintering alumina: effect of atmospheres, J. Am. Ceram. Soc. 45, 123-127 (1962).

[9] Jorgensen, P. J., and Westbrook, J. H., Role of solute segregation at grain boundaries during final-stage sintering of alumina, J. Am. Ceram. Soc. 47, 332-338 (1964).

[10] Roy, S. K., and Coble, R. L., Solubilities of magnesia, titania, and magnesium titanate in aluminum oxide, J. Am. Ceram. Soc. 51, 1-6 (1968).

[11] Aderson, R. C., General Electric Research and Development Center, Schenectady, N.Y. Private communication with one of the authors (JBW).

[12] Jorgensen, P. J., Stanford Research Institute, Palo Alto, California (formerly with General Electric Research and Development Center, Schenectady, N.Y.). Private communication with one of the authors (JBW).

[13] Wachtman, J. B., Jr., Tefft, W. E., Lam, D. G., Jr., and Stinchfield, R. P., Elastic Constants of Synthetic Single Crystal Corundum at Room Temperature, J. Res. Nat. Bur. Stand. (U.S.), 64A (Phys. and Chem.), No. 3, 213-228 (May-June 1960).

[14] Swanson, H. E., Cook, Marlene, Isaacs, Thelma, and Evans, Eloise, Standard X-ray Diffraction Powder Patterns, Nat. Bur. Stand. (U.S.), Circ. 539 (1960), p. 3.

[15] Paretzkin, B., National Bureau of Standards, private communication with the authors.

[16] Dickson, R. W., and Spinner, S., An Improved Method for the Determination of Torsional and Flexural Resonance Frequencies of Cylindrical Specimens, Journal of Materials 3, 716-724 (1968). 
「17〕 Wachtman, J. B., Jr., and Tefft, W. E., Effect of suspension position on apparent values of internal friction determined by Forster's Method, Rev. Sci. Inst. 29, 517-520 (1958).

[18] Wachtman, J. B., Jr., Tefft, W. E., Lam, D. G., Jr., and Apstein, C. S., Exponential temperature dependence of Young's Modulus for several oxides, Phys. Rev. 122, 1754-1759 (1961).

[19] Tefft, W. E., Elastic constants of synthetic single crystal corundum, J. Res. Nat. Bur. Stand. (U.S.), 70A (Phys. and Chem.), No. 4, 277-280 (Mar.-Apr. 1960).

[20] Grey, D. E., Coordinating editor, American Institute of Physics Handbook (McGraw-Hill, 1963). See pages 3-64 and 3-118.

[21] Weast, R. C., editor-in-chief, Handbook of Chemistry and Physics, The Chemical Rubber Company, Forty-eighth edition (1967).
[22] Spinner, S., Stone, L., and Knudsen, F. P., Temperature Dependence of the Elastic Constants of Thoria Specimens of Varying Porosity, J. Res. Nat. Bur. Stand. (U.S.), 67C (Eng. and Instr.), No. 2, 93-100 (Apr.-June 1963).

[23] Wachtman, J. B., Jr., Scuderi, T. G., and Cleek, G. W., Linear Thermal Expansion of Aluminum Oxide and Thorium Oxide From $100^{\circ}$ to $1100{ }^{\circ} \mathrm{K}, \mathrm{J}$. Am. Ceram. Soc. 45, 319-32.3 (1962).

[24] Spinner, S., Reichard, T. W., and Tefft, W. E., A Comparison of Experimental and Theoretical Relations Between Young's Modulus and the Flexural and Longitudinal Resonance Frequencies of Uniform Bars, J. Res. Nat. Bur. Stand. (U.S.), 64A (Phys. and Chem.), No. 2, 147-155 (Mar.-Apr. 1960).

(Paper 75A3-659) 